\title{
The Effect of Switchable Additives on Colloidal Interactions Found in Oil Sands as Measured by \\ Chemical Force Spectrometry
}

Ying Yin Lau, Tamer Andrea, Philip G. Jessop, * and J. Hugh Horton*

Department of Chemistry, Queen's University, Kingston, Ontario, Canada K7L 3N6

Corresponding Author Emails: jessop@queensu.ca \& jhh@queensu.ca 
KEYWORDS: oil sands, carbon dioxide, clay, settling, surfaces

ABSTRACT After oil sands separations, settling of clays from aqueous tailings can be promoted by additives such as $\mathrm{Ca}^{2+}$ salts. However, if the liberated water is then recycled, these same additives in the water interfere with bitumen recovery in the separator. Therefore, we have tested $\mathrm{CO}_{2}$-triggered switchable additives to see whether they can switch back and forth between a form that is suitable for the separation stage and a form that promotes tailings ponds settling. $\mathrm{CO}_{2}$-triggered switchable additives can reversibly change water chemistry merely by introduction and removal of $\mathrm{CO}_{2}$, a benign trigger. Here, the effects of $\mathrm{CO}_{2}$ mediated switchable additives on colloidal interactions found in model oil sands were studied by chemical force spectrometry. Self-assembled monolayers (SAM) of 12-phenyldodecanethiol and 12mercaptododecanoic acid were used to chemically modify gold coated atomic force microscope (AFM) tips. These were subsequently used to study the adhesion force between the modified tips and the minerals silica and mica. The adhesion between the tips and the mineral substrates were studied in aqueous solutions of varying $\mathrm{pH}$; divalent cation concentration; and in the presence of cationic switchable additives of varying surfactant potency, both in the presence and absence of $\mathrm{CO}_{2}$. In the presence of $\mathrm{CO}_{2}$, the best additive promotes attractive forces while in the absence of $\mathrm{CO}_{2}$ the forces are repulsive. These results are discussed in the context of the mechanism of colloidal interactions in an oil sands system.

\section{INTRODUCTION}

Oil sands are sand beds containing viscous, high density bitumen and they represent one of the largest mining operations in the world today $[1,2]$. The amount of oil that can be recovered from the sands is on par with the world's total discovered medium and light gravity oils. Although the 
separation of bitumen from the sand and clay minerals is already practiced on a large scale, there is significant room for improvement in the water chemistry to optimize both the separation step and the later settling of the solid fines from the process water.

The liberation of bitumen from mineral surfaces, such as sands and clays, is governed by the interaction forces that exist between the bitumen and the mineral surface. In the current industrial process, developed by Clark in the 1920s, water chemistry is manipulated through the addition of chemical additives to change the nature of the bitumen/mineral interactions to allow the bitumen to be separated from the mineral component of oil sands[5,6]. However, the optimal water chemistry for extraction is detrimental for the settling of tailings, a later step in the operation. For example, the conditions of high $\mathrm{pH}$ and low ionic strength which are conducive to bitumen separation are the very opposite to those required to optimize the flocculation and settling of colloids within the tailings pond. This is problematic for the entire process because either the process water has to be purified or more chemicals must be added at the tailings stage to optimize the settling process. In addition, the differing conditions are a barrier if the water from the tailings ponds is to be recycled for extraction use, a desirable scenario to reduce the environmental impact and water consumption of mining operations.

$\mathrm{CO}_{2}$-triggered switchable surfactants may provide an alternative to the conventional process used today. These chemicals can reversibly change the water chemistry when $\mathrm{CO}_{2}$, a benign trigger, is added or removed from the system. The compounds are long chain alkyl amidines which can reversibly switch between a neutral demulsifier form and a cationic surface active form using $\mathrm{CO}_{2}$ as an external trigger (Figure 1) [5]. Treatment of aqueous solutions of these amidine compounds with 1 atmosphere of $\mathrm{CO}_{2}$ affords the amidinium bicarbonate salt, which is a cationic surfactant. When the $\mathrm{CO}_{2}$ is removed by heating of the solution and/or by flushing it 
with an inert gas $\left(\mathrm{N}_{2}, \mathrm{Ar}\right.$, or air), the process is reversed to transform the surfactant back to its demulsifier form. We postulated that, by switching between a cationic surfactant state to a neutral demulsifier state, these switchable surfactants would be able to meet the conflicting requirements for promoting bitumen extraction and tailings ponds settling. The surfactants, while they are in the neutral state, would promote or at least not impede the separation of particles and bitumen droplets during the bitumen extraction stage of the process. Then, after they have been switched to the cationic state, they would promote the settling of the solids in the aqueous suspension sent to the tailings ponds. The work described in this paper was designed to evaluate this hypothesis.

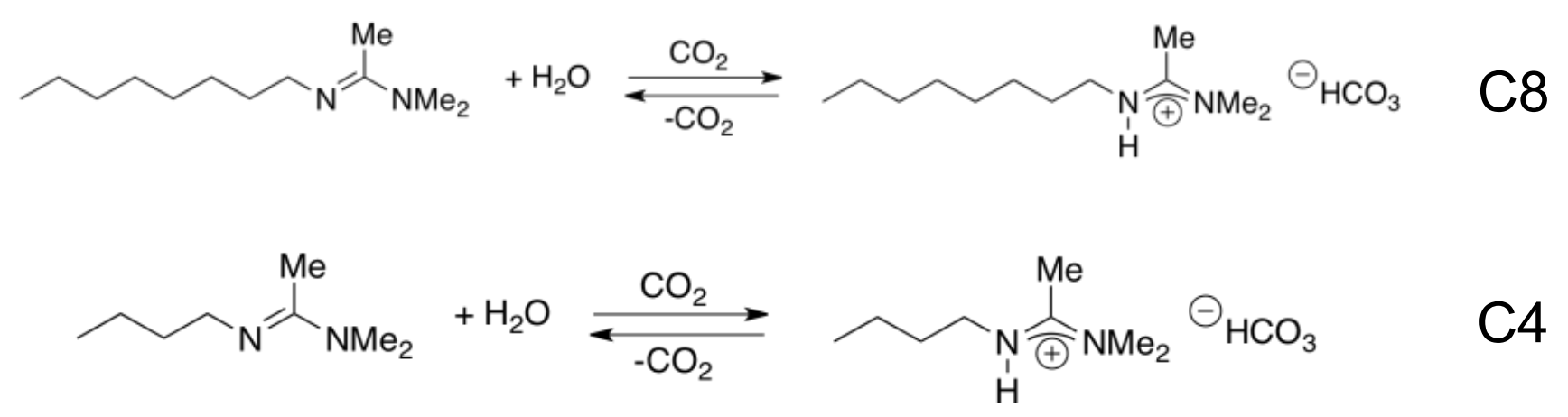

Figure 1. Switchable surfactant N'-octyl-N,N-dimethylacetamidine (C8) in neutral form (left) and surfactant form (right). The structurally similar compound N'-butyl-N,Ndimethylacetamidine (C4), which has too short an alkyl chain to be a good surfactant, is also shown in its neutral and protonated forms.

In this study, adhesion forces between bitumen and mineral surfaces were modeled and studied by chemical force spectrometry (CFS), particularly to investigate how switchable additives may be used to control these interactions which are crucial to the bitumen liberation 
phase of the oil sands extraction process. The Alberta oil sands are composed of bitumen (9$13 \%)$, water (3-7\%), and mineral solids (80-85\%), consisting of quartz sand, clays, muscovite mica, and other mineral fines. Clays (kaolinite, illite, chlorite, and montmorillonite) make up 15$30 \%$ of the mineral solids content[6]. Two organic functional groups commonly found in bitumen were selected to represent the bitumen: an aromatic phenyl group and a carboxylic acid group. Self assembled monolayers (SAM) terminated with these functional groups were formed on gold coated AFM tips for CFS experiments. While we originally intended to use samples of the clay minerals themselves to represent the clays in the oil sands, these minerals proved to be unusable in the chemical force experiments, due to extensive swelling in aqueous solution. Muscovite mica, which like the clays is a sheet-like phyllosilicate, was therefore used in our experiments to represent not only the mica in the oil sands but also as a model for the clays. A silica surface was used to represent the silica minerals (primarily quartz but also amorphous silica in the fines)[7]. Tip/sample interactions were analyzed as a function of $\mathrm{pH}$, in the presence of divalent cations (e.g. $\mathrm{Ca}^{2+}$, as used during the industrial process), and in the presence of switchable additives. $\mathrm{CO}_{2}$ switchable chemistry is mediated by changes in solution $\mathrm{pH}$ due to the dissolution of $\mathrm{CO}_{2}$. Thus, further measurements to determine the effects of solution $\mathrm{pH}$ on the interactions between SAM and mineral substrate, in the absence of switchable surfactant, were carried out. The literature related to oil sands chemistry indicates that divalent cations decrease bitumen recovery through the promotion of adhesion between the bitumen and sand moieties. The divalent cation both collapses the electrical double layer and shields the two negatively charged surfaces to increase adhesion[8.9]. Calcium sulfate, a common additive to oil sands tailings, was used in our CFS studies to investigate how well our model systems would serve in mimicking the response of real oil sands to charged additives. 


\section{EXPERIMENTAL SECTION}

\section{Synthetic Methods}

The synthesis of 12-phenyldodecanethiol was accomplished using previously published literature methods [10-12]. The ${ }^{1} \mathrm{H}-\mathrm{NMR},{ }^{13} \mathrm{C}-\mathrm{NMR}$ and mass spectra (high res, $\mathrm{EI}^{+}$) match those reported in the literature [10]. The NMR and mass spectra show that the product is a mixture of the thiol and the corresponding disulfide (3:1 ratio by $\left.{ }^{1} \mathrm{H}-\mathrm{NMR}\right)$ due to partial oxidation during the synthesis. However, it has been demonstrated in the literature $[13,14]$ that disulfides also self-assemble onto gold surfaces through scission of the sulfur-sulfur bond. Therefore, this material may still be used to create the desired self-assembled monolayers on gold.

N'-Butyl-N,N-dimethylacetamidine (C4) and N'-octyl-N,N-dimethylacetamidine (C8) were also synthesized by previously published literature methods[5]. 12-Mercaptododecanoic acid was purchased from Sigma Aldrich and used as received.

Silicon (111) wafers were purchased from Virginia Semiconductors Inc. These substrates were cleaned and oxidized with piranha solution ( $3: 1$ concentrated $\mathrm{H}_{2} \mathrm{SO}_{4}: 35 \mathrm{wt} \% \mathrm{H}_{2} \mathrm{O}_{2}$ in $\mathrm{H}_{2} \mathrm{O}$ ) for $1 \mathrm{~h}$ prior to being thoroughly rinsed with deionized water and drying under a stream of $\mathrm{N}_{2}(\mathrm{~g})$.

Muscovite mica (V-4 grade, SPI) was freshly cleaved prior to use. Double sided tape was adhered to the surface and subsequently pulled off to reveal a new basal surface for AFM force measurements.

\section{Instrumentation}


AFM force-distance curves were obtained using a PicoSPM instrument (Molecular Imaging, Tempe, AZ) and a Nanoscope IIE controller (Digital Instruments, Santa Barbara, CA). All experiments were conducted at $25^{\circ} \mathrm{C}$.

Gold-coated silicon nitride AFM tips (CSC-38, MikroMasch USA; nominal spring contant $\mathrm{k}=$ $0.08 \mathrm{~N} / \mathrm{m}$; tip radius $<10 \mathrm{~nm}$, as per manufacturer's specifications) were functionalized for adhesion force measurements by submerging the tips in a $1 \times 10^{-3} \mathrm{M}$ solution of 12phenyldodecanethiol ("phenyl tip") or 12-mercaptododecanoic acid ("acid tip") in isopropanol for $24 \mathrm{~h}$. The maximum applied force was $10 \mathrm{nN}$ and approach speed $800 \mathrm{~nm} / \mathrm{s}$ in all cases. Force measurements were conducted under aqueous conditions in solutions prepared using deionized water (18.2 M $\Omega$, Millipore).

The adhesive force between the tip and sample was determined from measuring the well depth of over 1000 force-distance curves under each experimental condition. This consisted of 200 measurements at each of 5 surface sites on the sample under each condition. The reported values are an average of all the measured adhesive forces and the errors are the calculated $95 \%$ confidence intervals. Two typical force curves in a solution of switchable amidine $\mathrm{C} 4$, in the presence and absence of $\mathrm{CO}_{2}$, are shown in Figure 2 for the interaction of a 12mercaptododecanoic acid tip with the mica substrate. The cantilever force constants were determined from the cantilever geometry[15,16] acquired using scanning electron microscope (SEM) images of the AFM tips taken before use. A typical set of SEM images for the tips can be found as the inset to Figure 2.

The absolute adhesion force values in these CFS experiments are dependent on the number of functional groups available for interactions with our substrates (arising from the surface coverage of the SAM on the AFM tip). Tips may also become damaged through the course of an 
experiment. To minimize these effects, we chose to use the same AFM tip for a given series of experiments (ex. switchable additive with and without $\mathrm{CO}_{2}$ ) and comparisons were made between the two different experimental conditions to establish the relative difference in adhesion force. We also tested the reproducibility of the measurements using two different tips under the same set of experimental conditions; a typical example of the results is shown in Table 1, for the interaction between an acid-terminated tip and silica substrate. Within experimental error, the forces measured are the same for both tips.

The chemical force titration experiments were conducted using freshly prepared unbuffered aqueous solutions of $\mathrm{pH}$ ranging from 3 to 11 . To modify the $\mathrm{pH}$, addition of $1.0 \mathrm{M} \mathrm{NaOH}$ solution was used to achieve alkaline conditions and similarly a $1.0 \mathrm{M} \mathrm{HCl}$ solution was added to achieve acidic conditions. Unbuffered $\mathrm{pH}$ solutions were used to prevent unwanted interactions between the surface and the ionic species associated with the buffer. The $\mathrm{pH}$ values were checked before and after the experiment and the solutions were changed frequently to minimize changes in $\mathrm{pH}$ due to the dissolution of atmospheric $\mathrm{CO}_{2}$. Experiments were carried out under low ionic strength conditions and the only ions introduced into the system were from the use of $\mathrm{HCl}$ and $\mathrm{NaOH}$ for $\mathrm{pH}$ adjustment.

Table 1. A comparison of adhesion force data from two carboxylic acid-terminated AFM tips of differing cantilever force constant, $\mathrm{k}_{\mathrm{f}}$ on a silica surface, under otherwise identical conditions.

\begin{tabular}{l|c|c} 
Solution & \multicolumn{2}{|c}{ Adhesion Force $(\mathbf{n N})$} \\
(deionized water) & Tip 1 $\left(\mathrm{k}_{\mathrm{f}}=0.080 \mathrm{~N} / \mathrm{m}\right)$ & $\operatorname{Tip~} 2\left(\mathrm{k}_{\mathrm{f}}=0.072 \mathrm{~N} / \mathrm{m}\right)$ \\
\hline $\mathrm{pH}=4.0 \pm 0.2$ & $0.18 \pm 0.04$ & $0.20 \pm 0.05$ \\
$\mathrm{pH}=5.0 \pm 0.2$ & $0.08 \pm 0.05$ & $0.10 \pm 0.02$
\end{tabular}




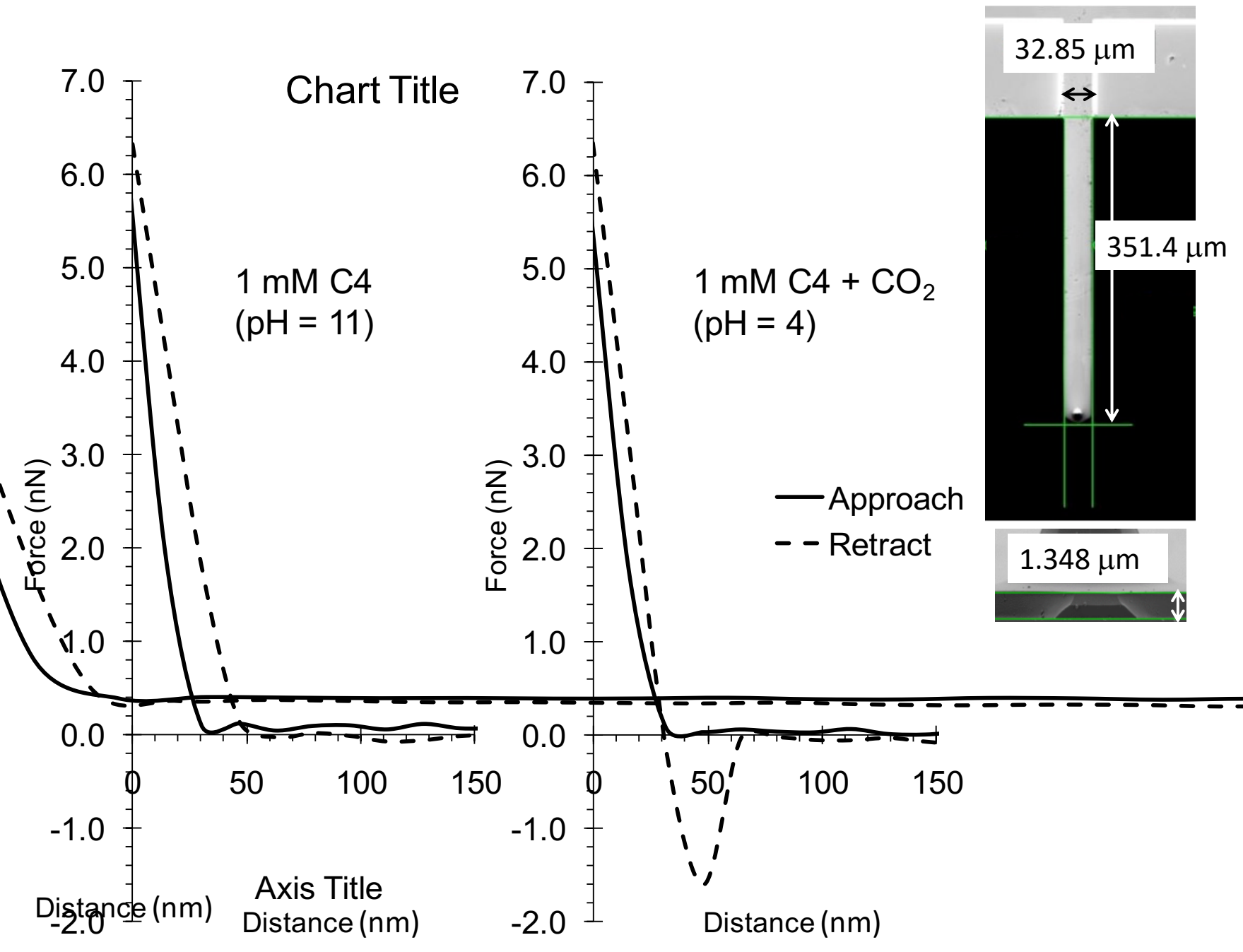

Figure 2. Typical force curve data observed in the chemical force spectrometry experiments.

Here, the forces between a tip terminated in 12-mercaptododecanoic acid and a mica substrate are shown in a solution of the switchable amidine $\mathrm{C} 4$ in the presence and absence of $\mathrm{CO}_{2}$. The inset shows an SEM image of the AFM tip, with the dimensions used to calibrate the force constant.

For experiments involving $\mathrm{CO}_{2}$ saturated solutions, the solutions were pretreated with $\mathrm{CO}_{2}$ prior to acquiring the force curves. Ultra pure $\mathrm{CO}_{2}$ (Supercritical $\mathrm{CO}_{2}$ Chromatographic Grade, 
Praxair) was bubbled through the solutions using a syringe for $30 \mathrm{~min}$. For these force measurements, the AFM was outfitted with an environmental cell that was filled with $\mathrm{CO}_{2}$ to maintain a $\mathrm{CO}_{2}$ atmosphere around the aqueous solutions during the experiment.

\section{RESULTS}

When switchable cationic surfactants are activated or deactivated through the addition or removal of $\mathrm{CO}_{2}$ from the system, the solution $\mathrm{pH}$ is varied. Chemical force titration profiles (plots of tip/sample adhesion as a function of $\mathrm{pH}$ ) were measured for AFM tips modified using both phenyl- and carboxylate-terminated SAMs with mica and silica substrates. These experiments are an important control case to monitor the background effect of any solution $\mathrm{pH}$ changes. The chemical force titration profiles for the silica substrate and the acid and phenyl terminated AFM tips are shown in Figure 3a. Note that the forces measured between silica substrate and the acid tip are scaled by a factor of 10 relative to the remaining data in Figure 3a. The force titration profiles obtained were quite different from those observed for a bare Au tip on silica (Figure 3c) or from those previously observed[17,18] by us for a bare Au tip on mica or on various SAMs on $\mathrm{Au}(111)$, indicating the SAM on the tip remained intact throughout these experiments.

The maximum adhesion force of $0.18 \pm 0.04 \mathrm{nN}$ was measured at $\mathrm{pH} 4$ in the chemical force titration profile between the acid tip and the silica substrate. The adhesion force drops off rapidly at higher and lower $\mathrm{pH}$ values, which is similar to force titration profiles previously observed in systems where the tip and sample interactions are dominated by hydrogen bonding forces[19,20]. The surface $p K_{a}$ of the acid-terminated SAM has been previously observed to be at approximately $4-5$, consistent with the $4.9 p \mathrm{~K}_{\mathrm{a}}$ of long-chain alkanoic acids in water[21]. 
Assuming that the silica substrate is negatively charged over much of the $\mathrm{pH}$ range studied, a large number of ionic $\mathrm{H}$-bonds may form at or below the surface $p \mathrm{~K}_{\mathrm{a}}$ of the tip, leading to the strong interactions observed in this $\mathrm{pH}$ range. At $\mathrm{pH}$ values above the $p \mathrm{~K}_{\mathrm{a}}$, the adhesion force diminishes sharply with increasing $\mathrm{pH}$, as would be expected because the tip is becoming increasingly negatively charged and it is interacting with a negatively charged substrate. Interestingly, the adhesion force increases again slightly at $\mathrm{pH} 11$. This was a reproducible trend, seen
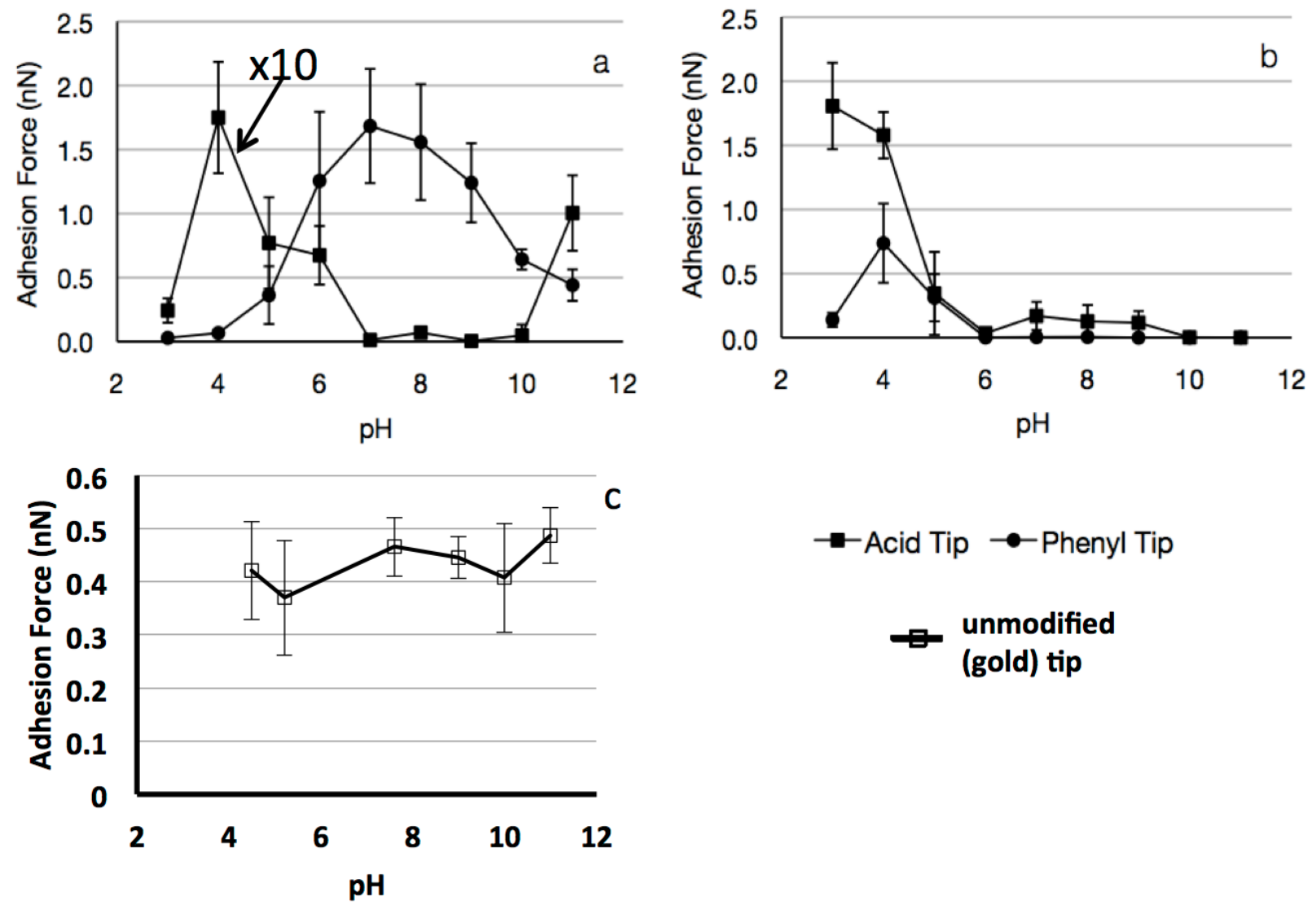

$\rightarrow$-Acid Tip $\rightarrow-$ Phenyl Tip

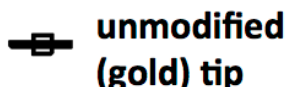

Figure 3. Chemical force titration curve showing the tip-sample adhesive force as a function of $\mathrm{pH}$ between an Au-coated AFM tip terminated with a SAM of 12-phenyldodecylthiol or 12mercaptododecanoic acid and (a) silica substrate or (b) mica substrate. The forces measured between the silica substrate and the acid tip are scaled by a factor of 10 relative to other three 
sets of data. Graph (c) shows a chemical force titration curve for the unmodified gold tip on a silica substrate (control case). The error bars represent the $95 \%$ confidence interval in the adhesion force as measured from an average of at least 1000 force-distance curves.

in independent experiments. Under these conditions, the $\mathrm{Na}^{+}$concentration is on the order of $10^{-3}$ $\mathrm{M}$, due to the high $\mathrm{NaOH}$ concentration required to achieve this high $\mathrm{pH}$. Both the silica substrate and the acid tip are expected to be negatively charged at $\mathrm{pH} 11$ and the presence of $\mathrm{Na}^{+}$ cations may serve to screen the two negatively charged surfaces.

The maximum adhesion force of $1.7 \pm 0.4 \mathrm{nN}$ for the phenyl-terminated AFM tip and the silica substrate was observed at $\mathrm{pH}$ 7. The chemical force titration profile shows that the adhesion force decreases gradually at higher and lower $\mathrm{pH}$ values. This result is consistent with hydrophobic forces dominating the tip-sample interaction.

The chemical force titration profiles for the mica substrate and the acid- and phenyl-terminated AFM tips are shown in Figure 3b. As with the silica substrate, a maximum adhesion force (1.6 \pm $0.2 \mathrm{nN}$ ) between the acid tip and the mica substrate was observed at a $\mathrm{pH}$ of 4 . This trend may again be attributed to hydrogen bonding interactions between the substrate and tip at $\mathrm{pH} 4$ and below, and charge repulsion at higher $\mathrm{pH}$. Adhesion forces between phenyl-terminated tip and mica substrate were weak through the entire $\mathrm{pH}$ range (Figure 3b). Again, hydrophobic interactions appear to be a main contributing factor in the tip-sample interaction.

A second series of experiments more explicitly explored the effect of ionic strength on tip/sample adhesion interactions. As noted earlier, the presence of divalent cations in solution effective for promoting flocculation of waste products in tailings ponds - have a detrimental effect in the bitumen recovery process, through increasing bitumen and sand adhesion. The 
divalent cation both collapses the electrical double layer and shields the two negatively charged surfaces to increase adhesion[19,20]. Adhestion forces between the various tip/sample pairs were thus measured as a function of calcium sulfate concentration.

As observed in Figure 4a, an upward trend in adhesion force with increasing $\mathrm{Ca}^{2+}$ ion concentration was seen for the carboxylic acid tip/silica substrate interaction. This result is consistent with observations in other model systems. Liu et al.[22] have previously shown that bitumen and silica can coagulate in solution containing greater than $0.1 \mathrm{mM} \mathrm{Ca}^{2+}$ ions. A similar finding has been reported by Takamura and Chow[23]. With the phenyl tip the interactions appear less strongly dependent on calcium concentration than in the acid tip case, indicating that it is the carboxylate sites of bitumen species that account for much of the increase in adhesive interactions in these systems.

When the same experiment was carried out on the mica substrate, as seen in Figure 4b, there was no systematic dependence of adhesion force on $\mathrm{Ca}^{2+}$ concentration with either AFM tip. The adhesion forces initially increase with the introduction of calcium sulfate, but decrease at higher concentrations.
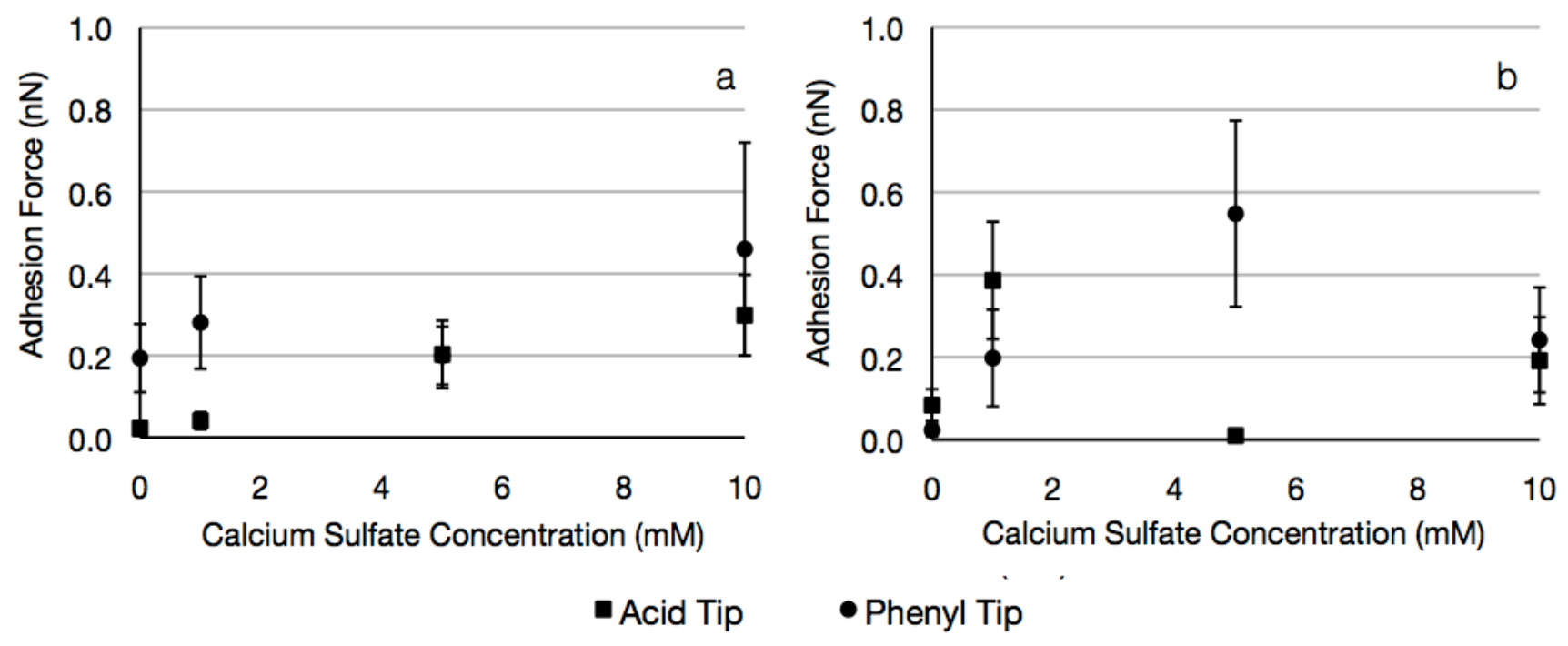
Figure 4. Chemical force spectrometry results showing the tip-sample adhesive force as a function of calcium sulfate concentration between a Au-coated AFM tip terminated with a SAM of 12-phenyldodecylthiol or 12-mercaptododecanoic acid and (a) silica substrate or (b) mica substrate in water of neutral $\mathrm{pH}$. The error bars represent the $95 \%$ confidence interval in the adhesion force as measured from an average of at least 1000 force-distance curves.

These results may be explained by the exchange of solution cations for those on the mica surface. Because the mica substrate contains mainly monovalent $\mathrm{Na}^{+}$or $\mathrm{K}^{+}$ion, the exchange would lead to a lower effective solution ionic strength, decreasing the adhesive forces measured. Such an exchange has been previously been reported in literature[24] and was confirmed in this case experimentally using X-ray photoelectron spectroscopy (XPS) (Figure 5). The substrates were submerged into calcium sulfate solutions for 15 minutes, rinsed thoroughly with deionized water, and dried prior to analysis. The XPS spectra show that the mica substrate surface was devoid of calcium before this treatment, but upon exposure to solution containing $\mathrm{Ca}^{2+}$ a $\mathrm{Ca} 2 \mathrm{p}$ peak appears and then grows in intensity with increasing calcium sulfate concentration. 


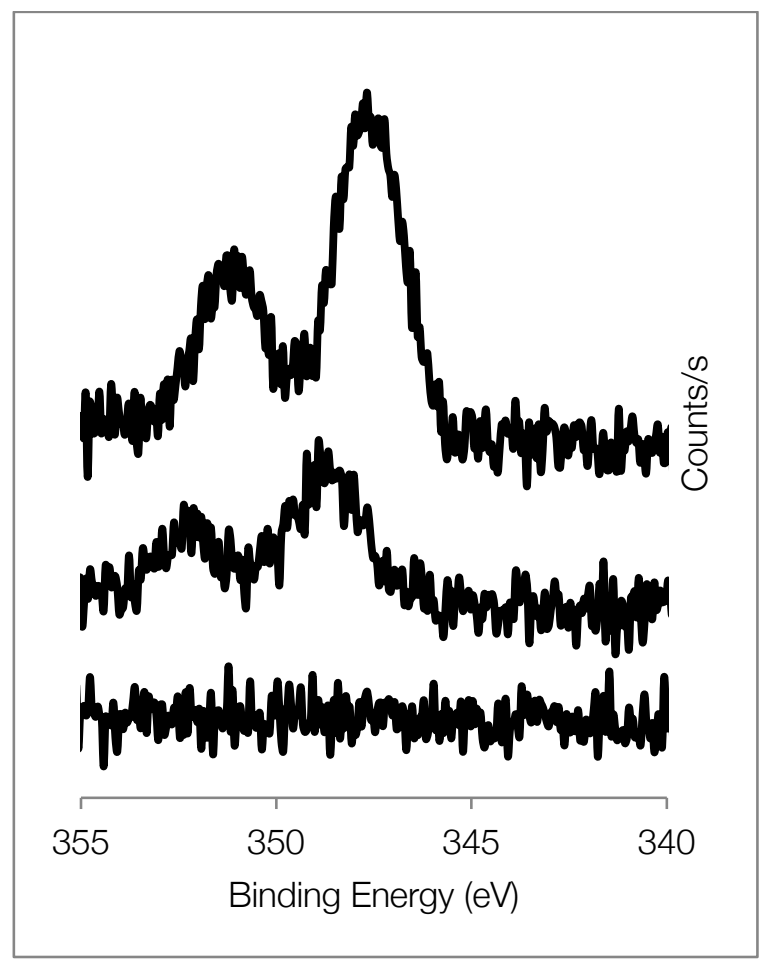

Figure 5. Calcium 2p XPS spectra of mica after submerging varying concentrations of calcium sulfate solutions (from top to bottom: $10 \mathrm{mM} \mathrm{CaSO}_{4}, 1 \mathrm{mM} \mathrm{CaSO}_{4}$, and $0 \mathrm{mM} \mathrm{CaSO}_{4}$ ).

Because the switchable surfactants use $\mathrm{CO}_{2}$ as a trigger, we determined, as a control experiment, the effects of exposure to $\mathrm{CO}_{2}$ on the adhesion force between surfaces in the absence of any switchable amidines. In particular, under the conditions in which switching occurs, $\mathrm{CO}_{2}$ reduces the solution $\mathrm{pH}$ to $4.0 \pm 0.2$. Table 2 compares the adhesion force between the various tip/sample combinations under $\mathrm{pH} 4.0$ conditions when the $\mathrm{pH}$ shift is induced by $\mathrm{CO}_{2}$ exposure or when the $\mathrm{pH}$ is adjusted by the addition of $\mathrm{HCl}$. The results presented in Table 2 show that the adhesion forces, within experimental error, are the same, indicating that carbonic acid alone has little or no effect on the system, other than that arising from the $\mathrm{pH}$ change. 
Table 2. A comparison of the effects of $\mathrm{CO}_{2}$ on tip/sample adhesion force versus $\mathrm{pH}$ effects.

\begin{tabular}{l|lc|lc}
$\begin{array}{l}\text { Additive } \\
(\mathrm{pH}=4.0 \pm 0.2)\end{array}$ & \multicolumn{4}{|c}{ Adhesion Force (nN) } \\
& Carboxylic Acid-terminated tip & \multicolumn{2}{c}{ Phenyl-terminated tip } \\
& Silica & Mica & Silica & Mica \\
\hline $\mathrm{CO}_{2}$ & $0.14 \pm 0.05$ & $1.07 \pm 0.25$ & 0 & $1.14 \pm 0.35$ \\
$\mathrm{HCl}$ & $0.18 \pm 0.04$ & $1.58 \pm 0.18$ & $0.07 \pm 0.02$ & $0.74 \pm 0.35$
\end{tabular}

In subsequent CFS experiments the cationic switchable surfactant, C8, was compared with $\mathrm{C} 4$, an amidine with a four carbon chain tail. Unlike $\mathrm{C} 8, \mathrm{C} 4$ is not a surfactant molecule in the presence of $\mathrm{CO}_{2}$ due to its short alkyl chain length[25]. However, both $\mathrm{C} 4$ and $\mathrm{C} 8$ can be protonated in aqueous solutions saturated with $\mathrm{CO}_{2}$ to yield a positively charged amidinium head group. Thus, comparison of $\mathrm{C} 4$ and $\mathrm{C} 8$ determines to what extent changes in adhesion force may be attributed to the surfactant properties or simply due to the presence of the protonatable amidine functionality.

The results from the CFS experiments in the presence of $\mathrm{C} 4$ are presented in Figure 6. A consistent trend was observed for all four tip/sample pairs. In the absence of $\mathrm{CO}_{2}(\mathrm{pH}=11)$, there was no interaction measured between the tip and the surface. Upon saturation of the aqueous solution with $\mathrm{CO}_{2}(\mathrm{pH}=5.0)$, the adhesion force increased, dramatically in the case of the mica substrate. 


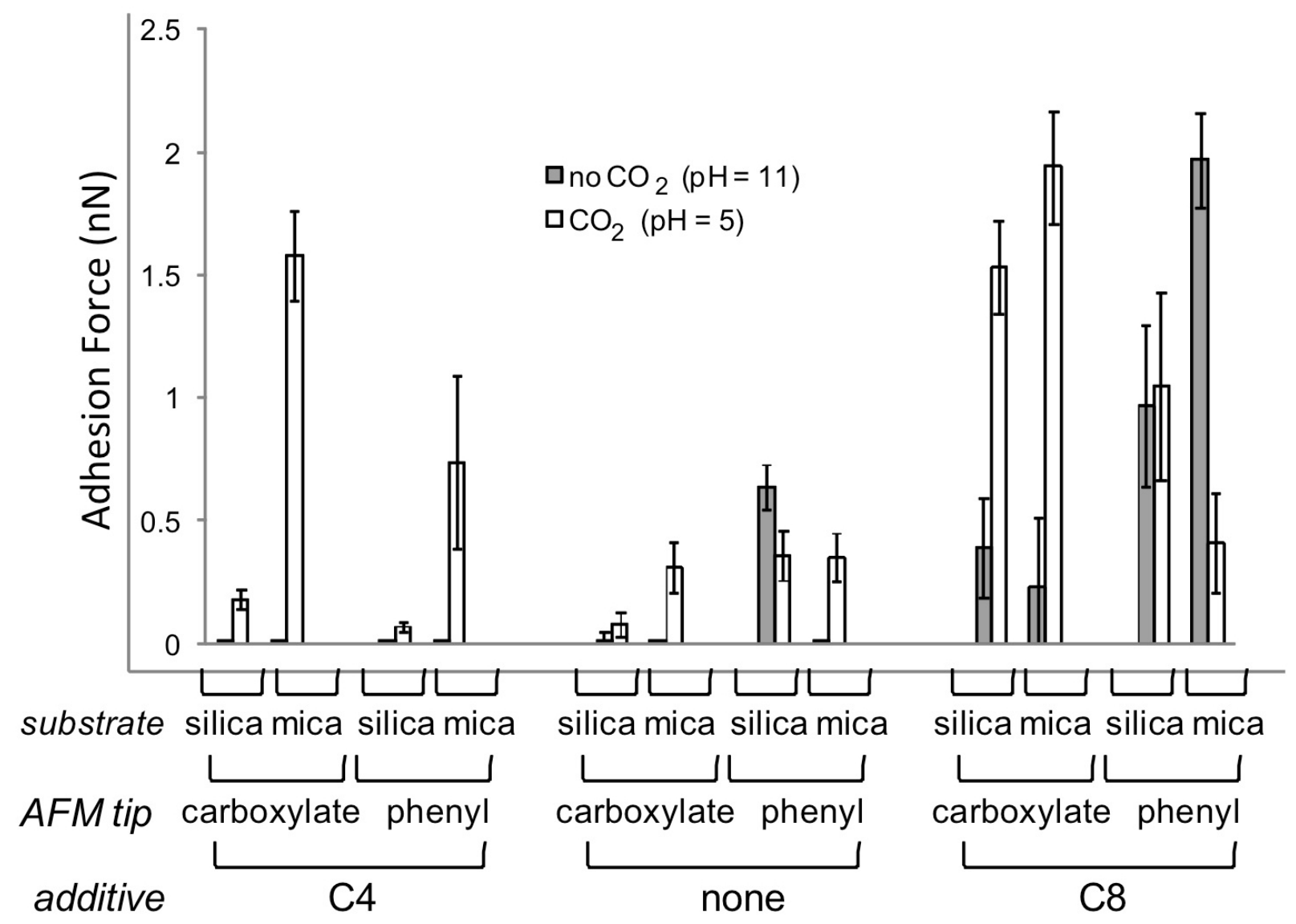

Figure 6. A comparision of the effects of switchable additives $\mathrm{C} 4$ and $\mathrm{C} 8$ on tip/sample adhesion force versus $\mathrm{pH}$ effects.

Because the $\mathrm{pH}$ of the solution changes upon addition of $\mathrm{CO}_{2}$, Figure 6 also shows the adhesion forces observed in the absence of the switchable amidine, but at the same $\mathrm{pH}$ (using $\mathrm{HCl}$ or $\mathrm{NaOH}$ ). For three of the four tip/sample pairs, the increase in adhesion force that is observed in the presence of $\mathrm{C} 4$ is greater than when the solution $\mathrm{pH}$ is modified by $\mathrm{HCl}$ or $\mathrm{NaOH}$, and in one pair (carboxylate/mica) the increase is dramatically greater. The observed modifications in adhesion force cannot be attributed to $\mathrm{pH}$ changes alone. 
Figure 6 also shows a similar set of data using C8, the active surfactant species. The addition of $\mathrm{CO}_{2}$ to the $\mathrm{C} 8$ solution causes a large rise in the attractive force for the carboxylate-terminated tip, but not for the phenyl-terminated tip. Again, the changes induced are greater than what may be attributed to changes in $\mathrm{pH}$ alone. Unlike the $\mathrm{C} 4$ case, the presence of $\mathrm{C} 8$ leads to significant adhesion forces for all four tip-sample pairs regardless of the presence or absence of $\mathrm{CO}_{2}$.

\section{DISCUSSION}

The observed trends for interactions involving the carboxylic acid tip in the presence of C4 may be driven by electrostatic interactions with the protonated version of the amidine molecules. It is important to note that the $\mathrm{pH}$ of the amidine solutions is higher than the $p \mathrm{~K}_{\mathrm{a}}$ of the acid tip (between 4 and 5), both in the presence and the absence of $\mathrm{CO}_{2}(\mathrm{pH} 5$ and $\mathrm{pH} 11$ respectively). Therefore, in both cases the tip should be negatively charged, as are both the mica and silica substrate surfaces. When the amidine is protonated, an electrostatic attraction may exist between the negatively charged tip and the positively charged additive head group (Figure 7, panel B). The amidinium cation may similarly be attracted to negatively charged sites on either substrate surface under these $\mathrm{pH}$ conditions. Such surfactant interactions with both mica and silica have previously been discussed in the literature: Sharma et al.[26] have shown through AFM imaging that distinct aggregates of a commercial cationic surfactant cetyltrimethylammonium bromide (CTAB) can adsorb on the surface of mica at $1 \mathrm{mM}$ concentration levels. Tyrode et al. [27] have similarly shown that CTAB can adsorb onto silica surfaces. Thus, the attractive interactions measured through CFS in the presence of $\mathrm{CO}_{2}$ may arise through a combination of ionic attraction causing the amidinium cations to coat the 
substrate and tip and hydrophobic interactions between the alkyl chains of the amidine molecules adsorbed onto both the tip and the substrate surface (Figure 7, Panel A and B). 

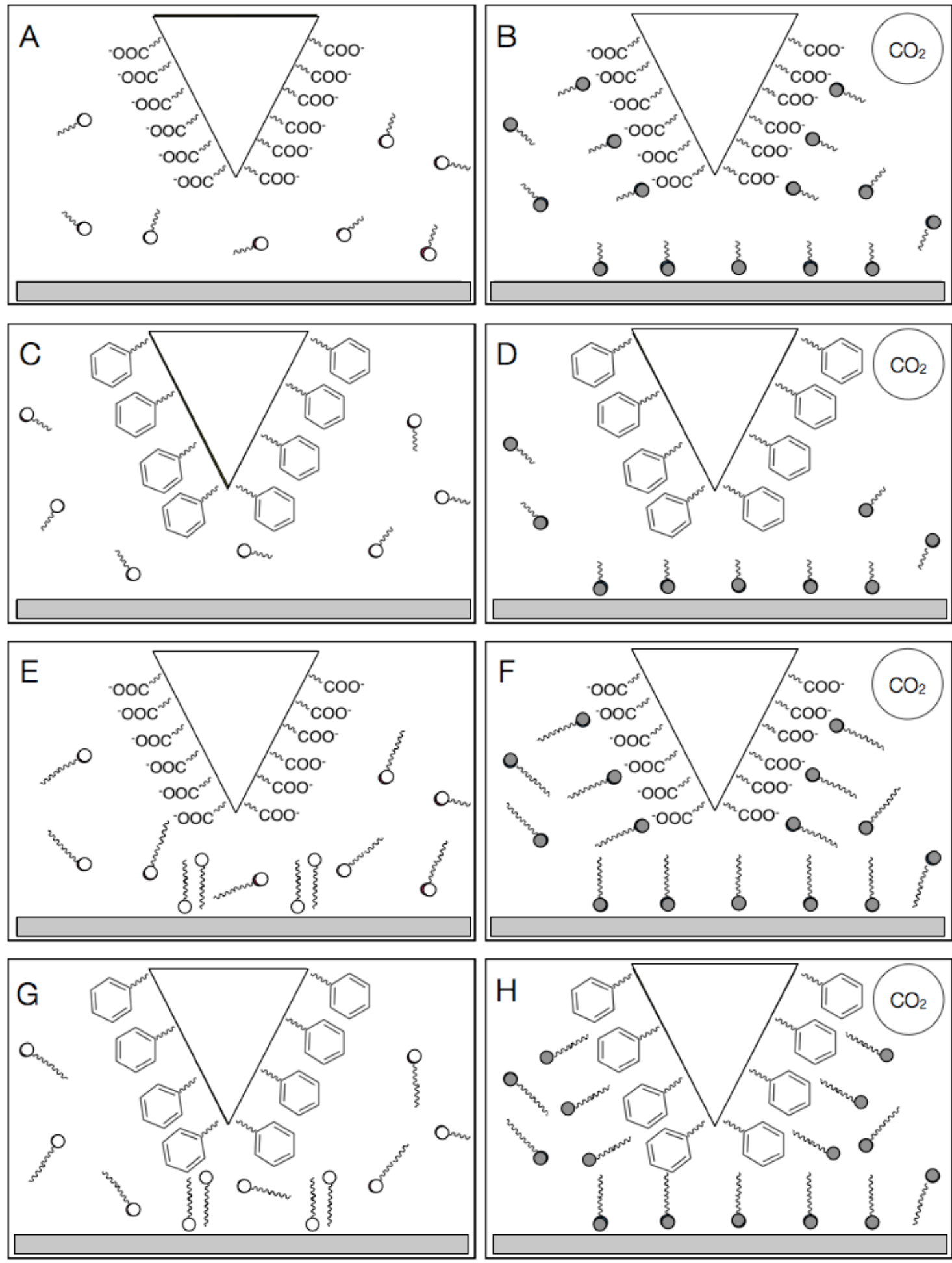

Figure 7. Proposed tip and substrate interactions in the presence of $\mathrm{C} 4$ (Panels A-D) and C8 (Panels E-H) without $\mathrm{CO}_{2}$ (left) and with $\mathrm{CO}_{2}$ (right). 
A similar interaction between a phenyl tip and a sample surface decorated with alkyl groups may also be envisioned (Figure 7, Panel C and D). Here, the tip is already hydrophobic due to the presence of the phenyl terminated SAM. Upon $\mathrm{CO}_{2}$ activation of $\mathrm{C} 4$, electrostatic attraction of the positively charged amidine head group to the negatively charged sample surface can expose the hydrophobic tails to the tip resulting in the measurement of hydrophobic attraction between the tip and sample.

The longer chain amidine species $\mathrm{C} 8$, which can act as a true surfactant when cationic, allows attractive interaction forces in the presence and absence of $\mathrm{CO}_{2}$. Being of longer chain length, they may self assemble at the surface to some extent due to van der Waals interactions, leading to the significant adhesive interaction forces that are measured (Figure 7, Panel E-H) under all $\mathrm{pH}$ conditions. While there is no direct evidence for this, as we note above there is some evidence for similar species self-assembling on the surface.

Introduction of $\mathrm{CO}_{2}$ to these aqueous systems protonates the $\mathrm{C} 8$ molecule and should result in an electrostatic attraction between the positively charged amidinium head group and the negatively charged substrate surface, as was proposed for $\mathrm{C} 4$ in the presence of $\mathrm{CO}_{2}$.

For interactions between the acid tip and both the silica and mica substrates in the presence of $\mathrm{C} 8$, an increase in adhesion force was observed when the aqueous solutions were $\mathrm{CO}_{2}$ saturated. This is believed to be due to adsorption of the switchable surfactant onto the surface of both the substrate and the tip, similar to that discussed for the $\mathrm{C} 4$ additive (Figure 7, Panel F). However, the net increase in adhesion force is not as strong when C8 is used compared to C4. As already noted, strong interactions already exist if $\mathrm{C} 8$ in its neutral form were to assemble onto the substrate surface. 
However, when the phenyl tip is in the presence of C8 the trends do not hold (Figure 7, Panel $\mathrm{G}$ and $\mathrm{H}$ ). Interactions with the silica substrate are not significantly affected by addition of $\mathrm{CO}_{2}$, while addition of $\mathrm{CO}_{2}$ actually decreases adhesion between the phenyl tip and the mica substrate. The main difference between the two cases can be seen when comparing Figure 7, Panels F and H. In the case of the carboxylate-terminated tip, both tip and sample are negatively charged. Thus, the surfactant may assemble, head down, on both tip and sample. This allows the hydrophobic tail groups to interdigitate as the tip and sample approach, increasing the extent of hydrophobic interaction and hence the adhesion force. However, for the phenyl tip, which is uncharged and itself hydrophobic, the surfactant's hydrophobic tail groups will be directed towards the tip, leaving the positively charged head groups, which are hydrophilic, to point outwards. These would repel the hydrophobic tail groups at the substrate surface.

The results from the CFS experiments suggest a mechanism by which amidines such as C4 and C8 can reversibly control adhesion between the various components of an oil sand. They also show that amidines such as $\mathrm{C} 4$ may be potentially useful as additives for the reversible manipulation of the water chemistry in oil sands extraction. In aqueous solutions containing C4 without $\mathrm{CO}_{2}$, the adhesion forces between the organic functionalized tips and the mineral surfaces were minimal. This suggests that this additive may be useful for decreasing adhesion between bitumen and mineral surfaces, thus facilitating bitumen liberation and flotation during the separation stage of oil sands processing. Further investigations to determine how these additives affect tailings performance are currently underway to elucidate if amidine switchable chemistry may be utilized in oil sands processing to facilitate the recycling of process water. 


\section{CONCLUSIONS}

Gold-coated AFM tips functionalized with 12-mercaptododecanoic acid or 12phenyldodecanethiol were used as models of bitumen surfaces for a study of adhesive interactions between these model bitumen surfaces and mica or silica. The parameters investigated included variations in $\mathrm{pH}$, changes in calcium sulfate concentration, addition of amidine additives $\mathrm{C} 4$ and $\mathrm{C} 8$, and the presence or absence of $\mathrm{CO}_{2}$. In the chemical force spectrometry experiments involving $\mathrm{C} 4$, the adhesion forces between the organic functionalized AFM probes and the mineral substrates were low in the absence of $\mathrm{CO}_{2}$, but an increase in adhesive interaction was observed when in the presence of $\mathrm{CO}_{2}$. The same trend was observed with experiments involving $\mathrm{C} 8$, but only when the acid tip was used. The lack of a $\mathrm{CO}_{2^{-}}$ triggered increase for the phenyl tip may be due to the hydrophobic tail of $\mathrm{C} 8$ being attracted towards the phenyl tip.

These results were useful in understanding fundamental colloidal interactions found in oil sands and how these switchable additives can affect these interactions. Of the two switchable additives studied, C4 was most consistent in switching on and off the adhesion interactions between all of our organic and mineral pairs, while C8 only showed that effect with the carboxylic tip. This suggests that this approach may potentially be useful for facilitating bitumen and mineral separation in the extraction phase of the industrial process. However, these model studies do not prove that the approach would be practical, economical, or effective in real systems. Further investigations using $\mathrm{C} 4$ in batch extraction experiments with real oil sands would be necessary to demonstrate in a more practical manner how bitumen liberation is affected by these potential process aids. 


\title{
ACKNOWLEDGMENT
}

We acknowledge Shell Canada and the Natural Sciences and Engineering Research Council of Canada for financial support. PGJ thanks the Canada Research Chairs Program.

\author{
ABBREVIATIONS \\ AFM, atomic force microscope; C4, N'-butyl-N,N-dimethylacetamidine; C8, N'-octyl-N,N- \\ dimethylacetamidine; CFS, chemical force spectrometry; CTAB, cetyltrimethylammonium \\ bromide; SAM, self-assembled monolayer; XPS, X-ray photoelectron spectroscopy.
}

\section{REFERENCES}

[1] Berkowitz, N.; Speight, J. Fuel 1975, 54, 138.

[2] Kasongo, T.; Zhou, Z.; Xu, Z.; Masliyah, J. Can. J. Chem. Eng. 2000, 78, 674.

[3] Clark, K.; Trans. Can. Inst. Min. Metall. 1944, 47, 257.

[4] Masilyah, J.; Zhou, Z.; Xu, Z.; Czarnecki, J.; Hamza, H. Can. J. Chem. Eng. 2004, 82, 628.

[5] a) Liu, Y.; Jessop, P.G.; Cunningham, M.; Eckert, C.; Liotta C. Science 2006, 313, 958. b) Fowler, C. I.; Jessop, P. G.; Cunningham, M. F. Macromolecules 2012, 45, 2955-2962. c) Scott, L.; Robert, T.; Harjani, J. R.; Jessop, P. G. RSC Advances 2012, 2, 4925-4931.

[6] Gupta, V.; Miller, J.D. J. Coll. Inter. Sci. 2010, 344, 362.

[7] Majid, A.; Argue, S.; Boyko, V.; Pleizier, G.; L’Ecuyer, P.; Tunney, J.; Lang, S. Coll. Surf. A 2003, 224, 33 . 
[8] Iler, R.K. Chemistry of Silica-Solubility, Polymerization, Colloid and Surface Properties and Biochemistry, John Wiley \& Sons: Hoboken, U.S.A., 1979.

[9] Maslova, M.V.; Gerasimova, L.G.; Forsling, W. Colloid J. 2004, 66, 322.

[10] Lee, S.; Puck, A.; Graupe, M.; Colorado, R.; Y.S. Shon, Jr.; Lee, T.R.; Perry, S.S. Langmuir 2001, 17, 7364.

[11] Speziale, J. J. Org. Syn. Coll. 1963, 4, 396.

[12] Frank, R.; Smith, P. J. Am. Chem. Soc. 1946, 68, 2103.

[13] Nuzzo, R.; Allara, D. J. Am. Chem. Soc. 1983, 105, 4481.

[14] Bain, C.; Bieyuck, H.; Whitesides, G. Langmuir 1989, 5, 723.

[15] Liu, W.; Bonin, K.; Guthold, M. Rev. Sci. Instrum. 2007, 78, 063707.

[16] Green, C.P.; Lioe, H.; Cleveland, J.P.; Proksch, R.; Mulvaney, P.; Sader, J.E. Rev. Sci. Instrum. 2004, 75, 1988.

[17] Omoike, A.; Horton, J.H. Langmuir 2000, 16, 1655.

[18] Kreller, D.I.; Gibson, G.; Novak, W.; Van Loon, G.W.; Horton, J.H. Coll. Surf. A 2003, $212,249$.

[19] van der Vegte, E.W.; Hadziioannou, G. J. Phys. Chem. B 1997, 101, 9563.

[20] van der Vegte, E.W.; Hadziioannou, G. Langmuir 1997, 13, 4357.

[21] Dean, J.A. Lange's Handbook of Chemistry, $15^{\text {th }}$ Edition, McGraw-Hill: New York U.S.A., 1999. 
[22] Liu, J.; Xu, Z.; Masliyah, J. J. Coll. Inter. Sci. 2005, 287, 507.

[23] Takamura, K.; Chow, R.S. J. Can. Pet. Technol. 1983, 22, 22.

[24] Xu, L.; Salmeron, M. Langmuir 1998, 14, 5841.

[25] Jessop, P.G. Reversibly switchable surfactants and methods of use thereof . U.S. Patent 11/599,623, August 21, 2008.

[26] Sharma, B.; Basu, S.; Sharma, M. Langmuir 1996, 12, 6506.

[27] Tyrode, E.; Rutland, M. W.; Bain, C. D. J. Am. Chem. Soc. 2008, 130, 17434. 
